\section{ECONOMICS}

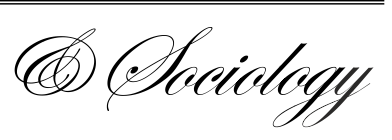

Gonzálvez-Gallego, N., \& Pérez-Cárceles, M.C. (2021). Does goodness of governance dissuade citizens from using cryptocurrencies?. Economics and Sociology, 14(1), 11-27. doi:10.14254/2071-789X.2021/14-1/1

\title{
DOES GOODNESS OF GOVERNANCE DISSUADE CITIZENS FROM USING CRYPTOCURRENCIES?
}

\author{
Nicolás Gonzálvez-Gallego \\ San Antonio Catholic University of \\ Murcia, \\ Murcia, Spain \\ E-mail:ngonzalver@ucam.edu \\ ORCID 0000-0002-0230-1195

María Concepción Pérez-
Cárceles
University Centre of Defense,
San Javier (Murcia), Spain
E-mail:
concepcion.perę@,cud.upct.es
ORCID 0000-0002-7262-3413

Received: April, 2020

1st Revision: January, 2021

Accepted: February, 2021

DOI: $10.14254 / 2071-$

789X.2021/14-1/1

JEL Classification: $\mathrm{O} 33$, O38, K42

\begin{abstract}
Cryptocurrencies are an increasing concern for national governments and international institutions. Anonymity, real-time transactions, together with the lack of intermediaries and control from financial and economic authorities make them appealing to criminals. Despite of the global efforts for standardizing the approach to cryptocurrencies, there are several risks identified and the way governments are facing them is not uniform. This paper analyzes the relation between goodness of governance and the use of cryptocurrencies on a sample of 33 countries. The results confirm that goodness of governance, by itself, dissuades people from holding and using cryptocurrencies. Additionally, our findings show that this effect relies on different governance factors, depending on how extended the use of cryptocurrencies is.
\end{abstract}

\section{Introduction}

Keywords: cryptocurrencies, corruption, governance.

In recent years, cryptocurrencies are receiving increasing attention since they are leading an innovation process that is commonly understood as disruptive. It means that cryptocurrencies could potentially reshape economic sectors such as transactions and electronic payments (Baur et al., 2015, Christensen, 1997). Cryptocurrencies are usually considered a virtual asset, which is defined as a digital representation of value that can be digitally traded or transferred and can be used for payment or investment purposes (Financial Action Task Force, 2019). Explicitly, this organization dismisses to include digital representation of fiat currencies within this definition, thus, cryptocurrencies do not have a similar legal status tender. The development of cryptocurrencies started one decade ago (Nakamoto, 2008). Under the pseudonym of Satoshi Nakamoto, an individual or a group of people whose identity is still 
unknown created the Bitcoin, the very first of the alternative currencies, or 'altcoins'. In July 2019, there were more than 2,200 cryptocurrencies already, with a total market capitalization of $\$ 271,123,534,071$ (Coinmarketcap.com, 2019). It is difficult to determine the exact amount of cryptocurrency users. Last estimations in Q2 2019 revealed there were $41 \mathrm{mln}$ Blockchain wallet users (Blockchain.com, 2019). However, this figure can be lower because one single user may own more than one wallet. Some studies carried out in Europe, the USA, Canada and Japan show that between 2\%-9\% of their population hold cryptocurrencies (Rauchs et al., 2018). However, these studies must be approached with due caution, since they only surveyed developed countries.

Despite the interest of users and academia in cryptocurrencies is quite recent, their fundamentals are rooted in the proposal built by Chaum (1983), usually cited as the starting point of cryptoassets. This author raised a system of cryptographic payments based on three properties. First, the inability of third parties to determine time, beneficiary and the amount of payments made by an individual. Second, the ability of individuals to provide a proof of payment, or to determine the identity of a beneficiary under exceptional circumstances. Finally, the capability to stop the use of payments that have been reported stolen. This set of features aims to ensure pseudo-anonymity, independence from a central authority and protection against double spending attacks. Twenty-five years after the release of this paper, Bitcoin met those criteria for the first time. Thus, it is considered that Bitcoin was the pioneer cryptocurrency (Narayanan, 2016). To know more on the history of cryptocurrencies, consider reading Wolfson (2015).

Governments should act now to take advantage of the beneficial properties that blockchains can bring to society, but also in order to minimize their potential risks (Maupin, 2017). There are several policy areas of concern regarding cryptocurrencies: consumer protection, financial stability, monetary policy and taxation (Choo, 2015). In this paper, we focus on the potential misuse of cryptocurrencies for illicit activities such as corruption. Houben and Snyers (2018) analyzed how certain features such as anonymity, cross-border nature and lack of central intermediaries, increase the risk of cryptocurrencies to be used for the purposes related to corruption, tax evasion and money laundering. The way national governments are regulating these new assets and their risks is heterogeneous. The regulatory response is linked to the local cryptoassets activity. Although there is a general lack of specific legislation on cryptocurrencies, in jurisdictions with high cryptocurrency activity, retrofitted regulations are largely extended, while in those with lower level of activity, cryptocurrencies remain unregulated or they depend on non-bespoke regulation (Blandin et al., 2019). Besides, in some countries, such as the United Arab Emirates and Vietnam, they are illegal, and in some others like China, Taiwan and Thailand, among others, they are implicitly banned. Regarding taxes and illicit activities, just a minor group of countries (Australia, Denmark, Canada, Japan, Switzerland) developed cryptocurrencies-related pieces of legislation that cover both areas. Indeed, most of developed countries just apply tax laws (e.g., Spain, the United Kingdom, Norway) or anti money-laundering and anti-terrorism legislation (e.g., Czech Republic, Estonia, Singapore) (The Law Library of Congress, 2018). This task is complex since, as suggested by Choohan (2017), an independent control and oversight of cryptocurrencies, similar to the one existing for fiat currencies, is redundant by the nature of cryptocurrencies themselves. Although there are papers and reports that address the risks of cryptocurrencies associated to corruption and bribery, due to the characteristics of these assets and activities, it is hard to test the link between corruption and the use of cryptocurrencies. As agreed by different authors, governance initiatives are relevant for providing solutions to those risks (Dierksmeier and Seele, 2018). One of the most noticeable legal instruments in this field is Bitlicense. Bitlicense is a commonly used term that refers to the set of licenses that entitle a 
business to carry out economic activities that involve virtual currencies. Those licenses are issued by the New York State Department of Financial Services (NYSDFS). They cover a wide range of activities, such as storing virtual currencies on behalf of third parties; financial transactions; or the issue, control and administration of virtual currencies (NYSDFS, 2015). Bitlicense is considered a relevant step in regulation of cryptocurrencies. However, some constraints are dissuading businesses and people from using cryptoassets. As stated by Chohan (2018), the main restriction is related to the fact that companies have to identify and report any user potentially involved in any dubious activity, even if the user or the firm is not a U.S. resident. It may avoid criminals to use cryptocurrencies but also ordinary citizens could dismiss its use due to privacy concerns.

The aim of this paper is to study whether countries with weaker and more tolerant institutions and regulations to corruption are more conducive environments for the use of cryptocurrencies than those countries with stronger and more effective governments. If so, it will be possible to approach empirically the hookup between the use of cryptocurrencies and illicit economic behaviors, as one of the main risks of those assets. This will provide policy makers with a relevant input, since we capture whether the global action of governing is having an effect on how popular the use of those virtual assets is among citizens, regardless of the existence of specific pieces of regulation on cryptocurrencies. This is a significant contribution, especially if we consider that most countries have not yet issued specific legal provisions for cryptocurrencies. Beyond this, they can get better insights on the effect of different areas of governmental management. Based on this analysis, public officers will be able to refine decision-making on legal aspects that affect how spread cryptocurrencies are among population. To study this potential association we drew on the idea of governance as proposed by Kaufmann et al. (2011). According to these authors, governance consists of traditions and institutions by which authority in a country is exercised. This includes the process of selection, monitoring and replacement of governments; the capacity of a government to effectively formulate and implement sound policies; and the respect of citizens and the state for the institutions that govern economic and social interactions among them. Governance is usually operationalized through a set of goodness of governance indicators collected by the World Bank. Consequently, we test the following hypothesis: the lower the goodness of governance of a country is, the higher the use of cryptocurrencies will be. We apply several statistical techniques to analyze the possible causal effect of goodness of governance on the percentage of people using cryptocurrencies. Also, we describe the use of cryptocurrencies in 33 countries.

This paper proceeds as follows. Section 1 approaches the notion of cryptocurrency. Section 2 addresses the link between cryptocurrencies and illicit practices such as corruption. Section 3 describes the data used. Section 4 discusses the empirical results. Finally, Section 5 concludes.

\section{Literature review}

\section{Cryptocurrencies}

Nowadays, due to the rise of cryptocurrencies, their definitions are being updated. Some authors emphasize technological features. For example, Velde (2013) defined Bitcoin as a peerto-peer currency that uses a complex cryptographic algorithm that requires a network of computers that allows the conduction of expensive mathematical processes. Litchfield (2015) defined a cryptocurrency as a string of code recorded on an open public ledger to allow peerto-peer exchanges that do not need any intermediaries. The verification of that code takes place 
within the Blockchain, a large network of computers that verifies each of the transactions of the ledger. Other authors highlight the economic characteristics of the cryptocurrencies, stating that they are currencies that can be transferred because all the potential users have the means and resources to verify past transactions, so that it is possible to avoid double-spending problems and all the transactions are publicly validated (Choo, 2015). From a more comprehensive approach, Chohan (2017) stated that a cryptocurrency is a digital asset built to work as a medium of exchange, based on the technology of cryptography, in order to ensure the transactional flow, as well as to control the creation of new units of currency.

To gain a better insight into how cryptocurrencies work in the context of economic transactions, we rely on Lansky (2018), who understands a cryptocurrency as a system that meets these six conditions:

- It does not require a central authority.

- It keeps the ownership of coined units of cryptocurrencies under control.

- It defines if additional units of cryptocurrencies can be created and how their ownership is determined.

- Ownership can only be proved cryptographically.

- It allows transactions in which the ownership of the cryptocurrency units change, but only when a third party issues a statement proving the current ownership of those units.

- If there are two simultaneous transferring instructions concerning the same units of cryptocurrency, the system will approve, at most, one of them.

Different factors can lead to a misuse of cryptocurrencies for illicit purposes linked to corruption. First, cryptocurrencies are coined electronically, in a decentralized way, so that they are neither backed nor oversighted by a governmental institution (Swartz, 2014). Second, there is a conflict between transparency and anonymity. In the Blockchain space, transactions are publicly validated, however, linking them to specific individuals or organizations involved is quite difficult. Indeed, there are some cryptocurrencies, such as Monero, which are nearly impossible to track. Since their blockchains are hidden, it is impossible to trace and identify individual transactions (Deepika, 2017). Third, transactions, use and withdrawal of funds take place in real time (Choo, 2015). As we analyzed in Section 2.2, those characteristics incentive the use of cryptocurrencies for illicit transactions associated to illegal funds.

\section{Cryptocurrencies, corruption and illicit practices}

Recently, many researchers have examined the factors affecting fraud (Omidi et al., 2017). In this line, Nye (1967) understood corruption as the behavior that deviates an individual or an organization from the duties of a public role because of private-regarding gains, which includes bribery and misappropriation; or violates rules against private influence. However, defining corruption is complex, especially when comparing the situation between countries which societies may have different approaches on what practices are considered as corruption. As explained by Sandholtz and Koetzle (2000), beyond this conceptual debate, it is agreed that corruption erodes core values of democracy, including decision-making that emerges from public processes established accordingly to well-known rules and equal access. These authors stated that, despite of the global efforts and international regulation, corruption persists, even in the most consistent and established democracies.

International organizations, such as Transparency International, align with those tenets. Since 1995, this institution evaluates perceived corruption across the world, based on experts and business people's inputs. For each country, they build the Corruption Perceptions Index, scoring on a scale from zero (highly corrupt) to 100 (very clean). In 2018, they studied 180 
countries and they found that two thirds of them scored below 50, with an average score of 43 . This report revealed that most of the countries made little to no progress and just 20 improved significantly in recent years (Transparency International, 2019).

Funds gained through these corrupt practices require of money laundering operations, a problem of a global dimension, since they allow financial transactions linked to illegal acts. They undermine world economy's welfare and performance (Buchanan, 2004). Consequently, efforts to eliminate those activities are also global through multilateral agencies, such as FATF, that provide countries with anti-money laundering (AML) international standards.

Before the rising of cryptocurrencies, criminals had to transfer their illegal funds through the central banking system. In this way, governments' regulation allowed the indirect control of money laundering, making illegal transfer more difficult (Gao, 2009). However, the use of Internet for money laundering is increasing, which makes the oversight of transfers a challenging task. This phenomenon is promoting the attractiveness of tax heavens and offshore bank accounts for moving illegal funds (Picard, 2011). Difficulties to trace money and identify the individuals participating in a given transaction are two relevant features of these operations boosted when using cryptocurrencies as a mean of transferring. This is the reason why emerging technologies associated to cryptocurrencies and the dark web may lead to new opportunities for corruption (World Bank, 2018). Illegal activities linked to cryptocurrencies, by their very nature, are difficult to be measured and quantified. One of the most remarkable attempts is the study authored by Foley et al. (2019). They profiled legal and illegal bitcoin's users according to a set of characteristics. Then, they estimated the size of the illicit activities and found that nearly half $(46 \%)$ of the transactions that involved bitcoin, which amounts to $\$ 76$ billion. Following the authors' conclusion, those figures revealed that the increasing adoption of cryptocurrencies as a payment method strongly relies on its use in supporting illegal transactions.

The European Banking Authority (EBA) identified more than 70 risks linked to cryptocurrencies. They highlight that cryptocurrencies can be potentially used for money laundering because transactions do not require personal identification and anonymity is guaranteed. In addition, the EBA warned about criminals using cryptocurrencies exchanges to avoid regulation, evade taxes and trade in illegal commodities. And, even if those illegal practices are detected, it is difficult for governments to enforce financial sanctions or embargos of illicit funds against other jurisdictions (European Banking Authority, 2014). In relation to these warnings, Böhme et al. (2015) asserted that early adopters of Bitcoin were organizations looking for features that were difficult to find in other alternatives: greater anonymity and lack of rules on the trading goods.

In the field of corruption and other illicit activities, different authors have studied the incentives to use cryptocurrencies. Without being exhaustive, in this section we review the most relevant factors that can lead to a misuse of cryptocurrencies. First, given the fact that cryptocurrencies do not have any legal tender status, the lack of supervision is critical for perpetrators to launder money from illegal activities like corruption (Brenig, 2015). Moreover, transactions do not required any financial intermediary, so that criminals can avoid the regulation concerning these agents. Together with this, users of cryptocurrencies elude AML and Know Your Customer (KYC) regulations. As a result, it is difficult for governments to control and monitor illicit activities (Lansky, 2018).

Second, anonymity is another incentive. While cryptocurrencies allow highly secured payments thanks to cryptography, their transactions are publicly visible, but not their participants, who remain anonymous. This is a stimulus to use cryptocurrencies to move, launder and hide funds from corruption and illegal activities (Adam and Fazekas, 2018; Swartz, 2014). It is possible to make cryptocurrency payments to anonymous accounts, which makes 
the control of corruption and crime increasingly difficult, especially if the transaction occurs between two different countries. In those cases, it is nearly impossible to prove that a certain criminal holds illegal funds (Lansky, 2018). Indeed, difficulties in tracking when different countries are involved in an operation, lead us to the third incentive: the ease for criminals of transferring funds to financial jurisdictions where accessing their funds and, at the same time, protecting them from confiscation (Gruber, 2015).

The fourth incentive is tax evasion. Cryptocurrencies meet the two traditional characteristics of a tax heaven: since they are under no jurisdiction, they are not subject to taxation at source; anonymity leads criminals to trade without disclosing their personal identification (Marian, 2013). Thus, it is easy for corrupt organizations and individuals to convert illicit funds into cryptocurrencies and transfer them to different countries in order to elude fiscal authorities (Albrecht et al., 2019).

Finally, transaction irreversibility is another incentive for corruption. Apparently, this characteristic is positive because it increases payment security. However, it could boost criminal activities (Sovtebov, 2018; Brill \& Keene, 2014). Payments are irreversible even when subject to a court order and it is impossible to enforce the withdrawal of illicit earnings unless the criminal provides the authorities with his or her account's private key (Lansky, 2018).

Given the ethical implications of cryptocurrencies, it is relevant to analyze the global regulatory trends (Dierksmeier \& Seele, 2018). As for cryptocurrencies' risks are global, supranational organizations such as the European Union (EU) or FATF are promoting a legislative alignment process that consists of agreeing common standards in all the jurisdictions. In some cases like EU Directives, European member states must implement them in their national regulatory framework, a process that may result in some divergences. There are also recommendations which compliance is not mandatory. An example of this is the report on cryptocurrencies submitted by the EBA to the European Commission in 2019. In addition to this, domestic regulations differ in their approach on cryptocurrencies. Blandin et al. (2019) studied 108 jurisdictions and they found that most of the countries decided to include a reference to cryptocurrencies within existing regulation or to apply former pieces of legislation. Only a minority of countries are opting for specific laws on cryptocurrencies.

Most of the governments and regulatory agencies rely on prior or current legislation to face challenges and risks associated to cryptocurrencies. Consequently, we study the global governance framework in order to test its potential effect on the use of cryptocurrencies. Therefore, in this analysis the existence of specific pieces of legislation on cryptocurrencies is not considered. We follow Kaufmann et al. (2011) who split goodness of governance in three dimensions. Each of them is made up of two indicators: the first dimension, the process by which governments are selected, monitored and is measured by Voice and Accountability (VA) and Political Stability and Absence of Violence/Terrorism (PS). A second dimension considers the capacity of the government to effectively formulate and implement sound policies, with the indicators Government Effectiveness (GE) and Regulatory Quality (RQ). The third dimension, the respect of citizens and the state for government institutions and the economic and social interactions among them, is evaluated by Rule of Law (RL) and Control of Corruption (CC).

\section{Methodological approach}

On the one hand, data on use of cryptocurrencies came from the Statista Global Consumer Survey 2019 for 33 countries. This online survey planned 2,000 respondents per country in 19 of them and 12,000 in the other 14 countries, from 18-64 years old. It included a yes/no question to ask the individuals if they currently use cryptocurrencies. On the other hand, Worldwide Governance Indicators for 2014, the latest available, were downloaded from the 
World Bank's data portal. Variations of these indicators perform progressive changes in national frameworks. So, we measure their influence on cryptocurrencies use in 2019.

Dimensional and global indicators have been developed from Kaufmann et al. (2011) definitions through the standardization of the aggregate of variables in each dimension. Following Pérez-Cárceles et al. (2019), dimensions and global indicators are considered as regressors to capture the whole effect of goodness of governance. The main objective is testing the following hypothesis: The goodness of governance of a country exerts a positive and significant influence on the proportion of population using cryptocurrencies. To this end, a methodological analysis is detailed by the following stages calculated by Stata software.

\section{Classification of sample units}

The countries in the sample are classificated by the median criterion:

$$
\begin{aligned}
& \text { If } \mathrm{y}_{\mathrm{i}} \leq \mathrm{Me} \rightarrow \mathrm{i} \in \text { low use } \\
& \text { If } \mathrm{y}_{\mathrm{i}}>\mathrm{Me} \rightarrow \mathrm{i} \in \text { high use }
\end{aligned}
$$

where $y_{i}$ is the value of the percentage of population using cryptocurrencies in the country $i$ and $M e$ is the descriptive statistics of the median of the percentage of population using cryptocurrencies. The groups generated are high use, where the countries have a proportion of population using cryptocurrencies superior to the median, and low use, where the proportion is inferior to the median.

\section{Testing homogeneous variances}

Normality assumption of variables is verified not only by their own structure, but also the normalization of their aggregates. Testing homogeneous variances is a previous requirement for selecting the most appropriate test of equal means. Variance analysis is developed by Levene's test (1960) that, based on the Snedecor's F distribution, is used to test homocedasticity of variances in two or more populations. In the present study, the null hypothesis of homocedasticity or equality of variances in two groups is tested versus the alternative hypothesis:

$$
\begin{aligned}
& H_{0}: \sigma_{\text {hu }}^{2}=\sigma_{\text {lu }}^{2} \\
& H_{1}: \sigma_{\text {hu }}^{2} \neq \sigma_{\text {lu }}^{2}
\end{aligned}
$$

where $\sigma_{\mathrm{hu}}^{2}$ and $\sigma_{\mathrm{lu}}^{2}$ are the variances of high use and low use groups, respectively.

\section{Testing equal means}

Student's t-test is a parametric test of equal means appropiate with a sample containing at least 30 units. In this study, the null hypothesis presents equality of means in the two groups:

$$
\begin{aligned}
& \mathrm{H}_{0}: \mu_{\mathrm{hu}}=\mu_{\mathrm{lu}} \\
& \mathrm{H}_{1}: \mu_{\mathrm{hu}} \neq \mu_{\mathrm{lu}}
\end{aligned}
$$

where $\mu_{\mathrm{hu}}$ and $\mu_{\mathrm{lu}}$ are the means of high use and low use groups, respectively. 


\section{Truncated regression model}

The estimation of regression models in both groups allows to compare the effects of the goodness of governance indicators on the porcentaje of population using cryptocurrencies. The truncated estimation is more appropriate that least-squares because of the purpose of that estimation. If the aim is to study the mean of percentage of cryptocurrencies' use conditional on the subsample of cryptocurrencies users, least-squares estimation is appropriate. However, if the interest is centered on the mean of percentage of cryptocurrencies' use regardless of cryptocurrencies use, least-squares estimates could be seriously misleading. This study develops a truncated regression that fits a model of a dependent variable on independent variables from a restricted part of a population (Cong, 1999).

Let $y=\beta_{0}+\beta_{1} x+\varepsilon$ the model to estimate, where $y$ is the percentage of use of cryptocurrencies, $x$ is a goodness of governance indicator and $\varepsilon \sim N\left(0, \sigma^{2}\right)$. If y has a normal distribution with mean $\mu$ and standard deviation $\sigma$, the density of the truncated normal distribution is:

$$
\mathrm{f}(\mathrm{y} / \mathrm{a}<\mathrm{y}<\mathrm{b})=\frac{\mathrm{f}(\mathrm{y})}{\mathrm{F}\left(\frac{\mathrm{b}-\mu}{\sigma}\right)-\mathrm{F}\left(\frac{\mathrm{a}-\mu}{\sigma}\right)}
$$

where $\mathrm{f}$ and $\mathrm{F}$ are the density and distribution functions of the standard normal distribution and $\mathrm{a}$ and $\mathrm{b}$ are the lower and the upper limit, 0 and 0.2 in this study, respectively. Compared with the variance of the untruncated variable, truncation reduces the variance.

Regarding the log likelihood, Greene (2012) and Davidson and MacKinnon (1993) provide introductions to the truncated regression model in:

$$
\log L=-\frac{n}{2} \log \left(2 \pi \sigma^{2}\right)-\frac{1}{2 \sigma^{2}} \sum_{i=1}^{n}\left(y_{i}-x_{i} \beta\right)^{2}-\sum_{i=1}^{n} \log \left\{F\left(\frac{b-x_{i} \beta}{\sigma}\right)-F\left(\frac{a-x_{i} \beta}{\sigma}\right)\right\}
$$

\section{Conducting research and results}

Table 1 defines the goodness of governance indicators and dimensions included in the analysis.

Table 1. Definition of indicators and dimensions

$$
\mathrm{GG}_{1}
$$

The process by which governments are selected, monitored, and replaced

\begin{tabular}{cl}
\hline VA & $\begin{array}{l}\text { Perceptions of the extent to which a country's citizens are able to participate in selecting } \\
\text { their government, as well as freedom of expression, freedom of association, and a free } \\
\text { media }\end{array}$ \\
\hline PS & $\begin{array}{l}\text { Perceptions of the likelihood that the government will be destabilized or overthrown by } \\
\text { unconstitutional or violent means, including politically-motivated violence and terrorism }\end{array}$ \\
The capacity of the government to effectively formulate and implement sound policies
\end{tabular}


$\mathrm{GG}_{3}$

The respect of citizens and the state for the institutions that govern economic and social interactions among them

\begin{tabular}{cl}
\hline RL & $\begin{array}{l}\text { Perceptions of the extent to which agents have confidence in and abide by the rules of } \\
\text { society, and in particular the quality of contract enforcement, property rights, the police, } \\
\text { and the courts, as well as the likelihood of crime and violence }\end{array}$ \\
\hline CC & $\begin{array}{l}\text { Perceptions of the extent to which public power is exercised for private gain, including } \\
\text { both petty and grand forms of corruption, as well as "capture" of the state by elites and } \\
\text { private interests. }\end{array}$ \\
\hline
\end{tabular}
Source: Kaufmann et al. (2011)

Table 2 shows descriptive statistics of the percentage of users of cryptocurrencies (CU) and the governance indicators and its dimensions. They present a range in units of a standard normal distribution between -2.5 and 2.5. Dimensional indicators, $\mathrm{GG}_{1}, \mathrm{GG}_{2}$ y $\mathrm{GG}_{3}$, have been developed from Kaufmann et al. (2011) definitions through the standardization of the aggregate of variables in each dimension. In the same way, a goodness of governance global indicator, $\mathrm{GG}$, is the standardization of the all the variables' aggregate. The range of the percentage of users of cryptocurrencies is wide $(0.06 \%$ to $20 \%)$. Regarding governance, either the three governance dimensions or the global indicator present positive average values in the whole sample. The dimension with the highest mean is $\mathrm{GG}_{2}$ (2.097), while $\mathrm{GG}_{1}$ shows the lowest mean value (1.292). All the individual indicators have positive means, showing RQ (1.069) and PS (0.366) the best and worst behavior, respectively

Table 2. Descriptive statistics

\begin{tabular}{cccccc}
\hline Variable & Mean & St. dev. & Min. & Max. & Range \\
\hline $\mathrm{CU}$ & 8.580 & 4.300 & 0.060 & 20.000 & $(0,100)$ \\
\hline $\mathrm{GG}$ & 5.290 & 4.590 & -4.000 & 11.170 & $(-15,15)$ \\
\hline $\mathrm{GG}_{1}$ & 1.292 & 1.370 & -2.500 & 3.150 & $(-5,5)$ \\
\hline $\mathrm{VA}$ & 0.927 & 0.659 & -1.090 & 1.690 & $(-2.5,2.5)$ \\
\hline $\mathrm{PS}$ & 0.366 & 0.763 & -1.800 & 1.590 & $(-2.5,2.5)$ \\
\hline $\mathrm{GG}_{2}$ & 2.097 & 1.450 & -0.550 & 3.900 & $(-5,5)$ \\
\hline $\mathrm{GE}$ & 1.028 & 0.717 & -0.290 & 1.980 & $(-2.5,2.5)$ \\
\hline $\mathrm{RQ}$ & 1.069 & 0.752 & -0.480 & 2.090 & $(-2.5,2.5)$ \\
\hline $\mathrm{GG}_{3}$ & 1.900 & 1.874 & -1.690 & 4.260 & $(-5,5)$ \\
\hline $\mathrm{RL}$ & 0.978 & 0.888 & -0.790 & 2.030 & $(-2.5,2.5)$ \\
\hline $\mathrm{CC}$ & 0.921 & 1.000 & -0.930 & 2.240 & $(-2.5,2.5)$ \\
\hline
\end{tabular}

Source: own calculation

Table 3 and Annexes I and II details the bivariate correlations between CU and the indicators and dimensions of goodness of governance. The pair CU-GE has the highest values of Pearson (-0.727) and Spearman (-0.695) correlation coefficients. While the indicators with the lowest Spearman and Pearson correlation are CU-VA (-0.620) and CU-GG 1 , respectively.

Table 3. Correlation between users of cryptocurrencies and governance indicators

\begin{tabular}{ccccccccccc}
\hline & $\mathrm{GG}$ & $\mathrm{GG}_{1}$ & $\mathrm{VA}$ & $\mathrm{PS}$ & $\mathrm{GG}_{2}$ & $\mathrm{GE}$ & $\mathrm{RQ}$ & $\mathrm{GG}_{3}$ & $\mathrm{RL}$ & $\mathrm{CC}$ \\
\hline $\begin{array}{c}\text { Spearm. } \\
\text { coeff. }\end{array}$ & -0.652 & -0.559 & -0.601 & -0.544 & -0.644 & -0.695 & -0.606 & -0.654 & -0.658 & -0.636 \\
\hline $\begin{array}{c}\text { Pearson } \\
\text { coeff. }\end{array}$ & -0.703 & -0.682 & -0.620 & -0.693 & -0.693 & -0.727 & -0.643 & -0.685 & -0.700 & -0.660 \\
\hline
\end{tabular}

All the correlation coefficients significant at $p \leq 0.01$

Source: own calculation 
Table 4 splits the sample of countries in two groups depending on the percentage of population using cryptocurrencies: above (high use) or below (low use) the median ( $8 \%$ ). The main aim of this classification is testing the hypothesis of significant differences in terms of goodness of governance between these groups.

Table 5 and Graph 1 show the mean values of the indicators and dimensions for the two groups. It is important to highlight that the mean values are lower in the group of high use of cryptocurrencies regardless of the indicator or dimension analyzed. On the contrary, those countries with lower use of cryptocurrencies always have a better average score. This result is in line with failing to reject the null hypothesis. With the aim of verifying this conclusion, following sections test equal means in the groups and compare estimated coefficients in both truncated regressions.

Table 4. Classification of countries by $\%$ of population using cryptocurrencies

\begin{tabular}{cc}
\hline High use & $\begin{array}{c}\text { Low use } \\
(\% \text { population } \geq 8)\end{array}$ \\
Ireland (IRE) & Japalation $<8$ (JPN) \\
Austria (AUT) & Germany (DEU) \\
Denmark (DEN) & Canada (CAN) \\
India (IND) & Sweden (SWE) \\
Portugal (PRT) & France (FRA) \\
Russia (RUS) & Finland (FIN) \\
Czech Republic (CZE) & United States of America (USA) \\
Netherlands (NLD) & Great Britain (GBR) \\
Spain (ESP) & South Korea (KOR) \\
Chile (CHL) & New Zealand (NZL) \\
Greece (GRC) & Italy (ITA) \\
Indonesia (IDN) & Lithuania (LIT) \\
Mexico (MEX) & Poland (POL) \\
South Africa (ZAF) & Norway (NOR) \\
Brazil (BRA) & Australia (AUS) \\
Colombia (COL) & Belgium (BEL) \\
Turkey (TUR) & \\
\hline
\end{tabular}

Source: Global Consumer Survey, Statista (2019)

Table 5. Descriptive statistics by groups

\begin{tabular}{lccccccccccc}
\hline & \multicolumn{10}{c}{ High use } \\
\hline & CU & GG & GG1 & VA & PS & GG2 & GE & RQ & GG3 & RL & CC \\
\hline Mean & 11.6 & 2.849 & 0.648 & 0.616 & 0.032 & 1.305 & 0.646 & 0.659 & 0.896 & 0.511 & 0.386 \\
S. dv. & 3.9 & 4.799 & 1.574 & 0.759 & 0.866 & 1.470 & 0.719 & 0.775 & 1.882 & 0.923 & 0.973 \\
Min. & 8.0 & -4.00 & -2.50 & -1.09 & -1.80 & -0.55 & -0.29 & -0.47 & -1.68 & -0.79 & -0.93 \\
Max. & 20. & 10.08 & 2.486 & 1.569 & 1.079 & 3.899 & 1.852 & 2.047 & 4.057 & 1.864 & 2.193 \\
\hline \multicolumn{10}{l}{} & \multicolumn{10}{c}{ Low use } \\
\hline Mean & 5.0 & 7.884 & 1.977 & 1.257 & 0.720 & 2.940 & 1.435 & 1.505 & 2.967 & 1.476 & 1.491 \\
S. dv. & 1.9 & 2.545 & 0.642 & 0.294 & 0.424 & 0.847 & 0.451 & 0.417 & 1.165 & 0.512 & 0.675 \\
Min. & 0.1 & 3.011 & 1.030 & 0.740 & 0.212 & 1.206 & 0.502 & 0.704 & 0.514 & 0.325 & 0.189 \\
Max. & 7.0 & 11.16 & 3.150 & 1.692 & 1.593 & 3.855 & 1.983 & 2.089 & 4.257 & 2.027 & 2.241 \\
\hline
\end{tabular}

Source: own calculation 


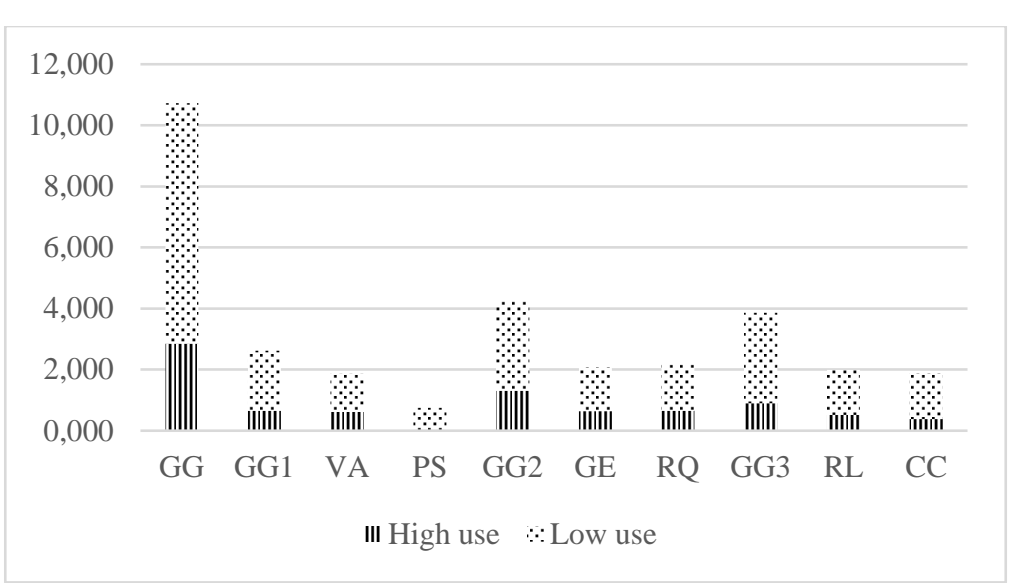

Graph 1. Comparison of governance indicators' averages Source: own calculation

\section{Regression models}

The estimation of regression models proposes alternative indicators as independent variables due to the high correlations even between the variables for each dimension (Appendix I). Moreover, dimensions and global indicator are also included to consider as much information about goodness of governance as possible, without generating collinearity among the regressors.

Table 6 contains the estimation of the goodness of governance effect on the percentage of population using cryptocurrencies in countries with high and low use, respectively. Truncated regressions are estimated considering alternative goodness of governance indicators. The appropriateness of the models is also validated because of the significance of the goodness of fit Wald's statistic in italics.

Table 6. Truncated regression models

\begin{tabular}{|c|c|c|c|c|c|c|}
\hline & \multicolumn{3}{|c|}{ High use } & \multicolumn{3}{|c|}{ Low use } \\
\hline & Coef. & $\mathrm{P}>|\mathrm{z}|$ & Wald $\chi_{1}^{2}$ & Coef. & $\mathrm{P}>|\mathrm{z}|$ & Wald $\chi_{1}^{2}$ \\
\hline VA & -1.566 & - & 1.680 & -1.852 & - & 1.370 \\
\hline Cons & 12.189 & $* * *$ & 0.195 & 7.313 & $* * *$ & 0.241 \\
\hline PS & -2.373 & $* *$ & 5.780 & -2.480 & $* *$ & 6.530 \\
\hline Cons & 11.429 & $* * *$ & 0.016 & 6.776 & $* * *$ & 0.011 \\
\hline $\mathrm{GE}$ & -2.824 & $* * *$ & 8.860 & -2.017 & $*$ & 4.640 \\
\hline Cons & 13.002 & $* * *$ & 0.003 & 7.885 & $* * *$ & 0.031 \\
\hline RQ & -1.781 & - & 3.050 & -2.022 & $*$ & 3.790 \\
\hline Cons & 12.331 & $* * *$ & 0.081 & 8.034 & $* * *$ & 0.052 \\
\hline RL & -1.999 & $* *$ & 6.540 & -1.629 & $*$ & 3.74 \\
\hline Cons & 12.197 & $* * *$ & 0.010 & 7.395 & $* * *$ & 0.053 \\
\hline $\mathrm{CC}$ & -1.762 & * & 5.490 & -1.185 & - & 3.350 \\
\hline Cons & 11.825 & $* * *$ & 0.019 & 6.756 & $* * *$ & 0.067 \\
\hline $\mathrm{GG}_{1}$ & -1.086 & $*$ & 3.670 & -1.468 & $*$ & 4.900 \\
\hline Cons & 12.007 & $* * *$ & 0.055 & 7.891 & $* * *$ & 0.027 \\
\hline $\mathrm{GG}_{2}$ & -1.172 & $* *$ & 5.410 & -1.060 & $*$ & 4.490 \\
\hline Cons & 12.700 & $* * *$ & 0.020 & 8.109 & $* * *$ & 0.034 \\
\hline $\mathrm{GG}_{3}$ & -0.951 & $* *$ & 6.100 & -0.713 & $*$ & 3.680 \\
\hline Cons & 12.013 & $* * *$ & 0.013 & 7.107 & $* * *$ & 0.055 \\
\hline GG & -0.366 & $*$ & 5.290 & -0.360 & $*$ & 4.690 \\
\hline Cons & 12.257 & $* * *$ & 0.021 & 7.828 & $* * *$ & 0.030 \\
\hline
\end{tabular}

$* * * \mathrm{p}<0.001, * * \mathrm{p}<0.010, * \mathrm{p}<0.050$

Source: own calculation 
If we observe the global indicator (GG), the conclusion about the influence on the use of cryptocurrencies is similar in the two groups. However, alternative regressions with specific indicators as independent variables show more accurate results. Regarding the high use group, the capacity of the government to effectively formulate and implement sound policies $\left(\mathrm{GG}_{2}\right)$ presents the highest and most significant coefficient among the dimensions, being Government Effectiveness (GE) the most relevant variable in the model. Voice and accountability and Regulatory quality have no effect on the use of cryptocurrencies. In terms of the low use group, the highest coefficient belongs to the process by which governments are selected, monitored, and replaced (GG1). Included in this dimension, Political Stability and Absence of Violence/Terrorism (PS) is the most significant variable in this group. Voice and accountability and Control of Corruption are not significant for those countries.

In general terms, policies and national strategies to control cryptocurrencies use should be oriented to improve Government Effectiveness, Political Stability and Absence of Violence/Terrorism and Rule of Law. Nevertheless, the relevance of these variables is always higher in high use countries. Then, goodness of government is more effective when a high percentage of population is using cryptocurrencies.

\section{Conclusion}

The aim of this paper is to explore the causal link between goodness of governance and the use of cryptocurrencies. To study this, descriptive and correlation analysis were ran. They showed significant relations between the percentage of individuals using cryptocurrencies and different goodness of governance indicators. Our empirical study reveals that significant crosscountry differences emerge in the percentage of population using cryptocurrencies between countries, depending on goodness of governance. In order to look into this effect, we measured the effect of governance on cryptocurrency adoption. Accordingly, our preliminary tests confirmed that countries where cryptocurrencies are more extensively used show a poorer performance in goodness of governance. However, a deeper insight was required, and we split the whole sample into two groups: high-use countries and low-use countries. Then, we carried out a truncated regression analysis for each of them.

First, regarding our main hypothesis, this study shows that the group of countries with higher goodness of governance have a lower percentage of users of cryptocurrencies, while their use is stimulated by a lower level of governance. This result confirms the theoretical relation that, both academia and institutions, established between cryptocurrencies and illicit practices. Although we cannot affirm that all the cryptocurrencies users are motivated to carry out illicit activities, we found that those countries with weaker institutions, quality of government and more tolerance towards corruption have a larger percentage of population that declares to use cryptocurrencies.

Second, and consistent with that reasoning, results also pose that exercising authority according to the principles of political stability, government effectiveness, regulatory quality, control of corruption and rule of law has a negative impact on the adoption of cryptocurrencies. This means that, although other factors must be studied as drivers for the adoption of cryptocurrencies, the general political and legal context has an effect on discouraging people from using those assets.

Third, the sub-sample analysis revealed that not all the governance indicators have the same effect in both groups. Improvements in providing public services and implementing policies, rule of law, and controlling corruption are expected to have a larger effect on discouraging the use of cryptocurrencies in high-use countries than in those with a lower percentage of population using cryptocurrencies. On the contrary, ability to participate in 
selecting the government and perceptions of civil freedoms, political stability and absence of violence and the implementation of policies that promote private sector development (RQ) rise as the indicators with the highest effect in persuading people from using cryptocurrencies. These results are useful for policy-makers and institutional managers, since we provide evidence beyond the fact that better governance leads to a lower use of cryptocurrencies. Specifically, our study leads public officers to improve decision making, since we have identified the specific significance and size of the impact of each of the areas of governance on the use of cryptocurrencies.

Fourth, we found high inter-indicator correlations that unveil the existence of an indirect and negative impact on the use of cryptocurrencies. When governments and institutions improve one of the areas of governance, ceteris paribus, other areas are reinforced too. As a result, the decrease in the number of users of cryptocurrencies will be higher, since a direct and indirect effect take place simultaneously.

Despite of the relevance of our findings, this study has several limitations. Our analysis captures the effect of goodness of governance on the adoption of cryptocurrencies, but other variables may affect it. Some countries have more crypto-friendly regulatory frameworks than others, which is the case of Spain and Denmark, and this could partially explain why their population are using cryptocurrencies more than in other countries. Future studies should consider both general issues, such as governance, and specific regulation in order to clarify how these two interact. Besides, in order to confirm our results, further longitudinal studies are necessary to study if changes in governance and in perception and control of corruption affect the number of users of cryptocurrencies.

\section{References}

Albrecht, C., Duffin, K. M., Albrecht, C., \& Morales Rocha, V. M. (2019). The use of cryptocurrencies in the money laundering process. Journal of Money Laundering Control, 22(2), 210-216.

Adam, I., \& Fazekas, M. (2018, December). Are emerging technologies helping win the fight against corruption in developing countries? Pathways for Prosperity Commission Background Paper Series; no. 21. Oxford, United Kingdom.

Baur, A. W., Bühler, J., Bick, M., \& Bonorden, C. S. (2015, October). Cryptocurrencies as a disruption? Empirical findings on user adoption and future potential of bitcoin and co. In Conference on e-Business, e-Services and e-Society, 63-80. Springer, Cham.

Blandin, A., Cloots, A. S., Hussain, H., Rauchs, M., Saleuddin, R., Allen, J. G., \& Zhang, B. Z. (2019). Global Cryptoasset Regulatory Landscape Study. Retrieved from https://www.jbs.cam.ac.uk/fileadmin/user_upload/research/centres/alternativefinance/downloads/2019-04-ccaf-global-cryptoasset-regulatory-landscape-study.pdf.

Blockchain (2019). Blockchain wallet activity. Retrieved from www.blockchain.com

Böhme, R., Christin, N., Edelman, B., \& Moore, T. (2015). Bitcoin: Economics, technology, and governance. Journal of Economic Perspectives, 29(2), 213-38. doi.org/10.1257/jep.29.2.213

Buchanan, B. (2004). Money laundering-a global obstacle. Research in International Business and Finance, 18(1), 115-127. doi.org/10.1016/j.ribaf.2004.02.001

Brenig, C., Accorsi, R., \& Müller, G. (2015, May). Economic Analysis of Cryptocurrency Backed Money Laundering. In ECIS. doi.org/10.18151/7217279

Bunjaku, F., Gorgieva-Trajkovska, O., \& Miteva-Kacarski, E. (2017). Cryptocurrenciesadvantages and disadvantages. Journal of Economics, 2(1). 
Brill, A., \& Keene, L. (2014). Cryptocurrencies: The next generation of terrorist financing?. Defence Against Terrorism Review, 6(1), 7-30.

Chaum, D. (1983). Blind signatures for untraceable payments. In Advances in cryptology (pp. 199-203). Springer, Boston. doi.org/10.1007/978-1-4757-0602-4_18

Chohan, U. W. (2017, August). Cryptocurrencies: a brief thematic review. doi.org/10.2139/ssrn.3024330

Chohan, U. W. (2018). Oversight and regulation of cryptocurrencies: BitLicense. Available at SSRN 3133342.

Choo, K. K. R. (2015). Cryptocurrency and virtual currency: Corruption and money laundering/terrorism financing risks? In Handbook of digital currency (pp. 283-307). Academic Press.

Cong, R. (1999). Truncated regression. Stata Technical Bulletin 52: 47-52. Reprinted in Stata Technical Bulletin Reprints, 9, pp. 248-255. College Station, TX: Stata Press.

Christensen, C. M. (2013). The innovator's dilemma: when new technologies cause great firms to fail. Harvard Business Review Press.

CoinMarketCap (2019). Cryptocurrency Active Market. Retrieved from http://www.coinmarketcap.com

Davidson, R., \& MacKinnon, J. G. (1993). Estimation and inference in econometrics, 534537. Oxford, United Kingdom: Oxford University Press.

Deepika, P., \& Kaur, E. R. (2017). Cryptocurrency: trends, perspectives, and challenges. International Journal of Trends in Research and Development, 4, 4-6. http://www.ijtrd.com/papers/IJTRD9620.pdf

Deloitte (2015). State-Sponsored Cryptocurrency: Adapting the Best of Bitcoin's Innovation to the Payments Ecosystem. Available

at: https://www2.deloitte.com/content/dam/Deloitte/au/Documents/financialservices/deloitte-au-fs-state-sponsored-cryptocurrency-180516.pdf.

Dierksmeier, C., \& Seele, P. (2018). Cryptocurrencies and business ethics. Journal of Business Ethics, 152(1), 1-14.

European Banking Authority (2014). Opinion on virtual currencies. Retrieved from https://eba.europa.eu/documents/10180/657547/EBA-Op-2014-

08+Opinion+on+Virtual+Currencies.pdf

Financial Action Task Force. (2019). Guidance for a Risk-Based Approach to Virtual Assets and Virtual Asset Service Providers, FATF, Paris. www.fatfgafi.org/publications/fatfrecommendations/documents/Guidance-RBA-virtualassets.html

Foley, S., Karlsen, J. R., \& Putniņš, T. J. (2019). Sex, drugs, and bitcoin: How much illegal activity is financed through cryptocurrencies?. The Review of Financial Studies, 32(5), 1798-1853.

Gao, S., \& Xu, D. (2009). Conceptual modeling and development of an intelligent agentassisted decision support system for anti-money laundering. Expert Systems with Applications, 36(2), 1493-1504. doi.org/10.1016/j.eswa.2007.11.059

Greene, W.H. (2012). Econometric analysis, 833-839. New York, United States: Pearson.

Gruber, Sara (2015). Trust, Identity, and Disclosure: Are Bitcoin Exchanges the Next Virtual Havens for Money Laundering and Tax Evasion?. Quinnipiac Law Review, 135-208.

Herbert, J., \& Litchfield, A. (2015, January). A novel method for decentralised peer-to-peer software license validation using cryptocurrency blockchain technology. Proceedings of the 38th Australasian Computer Science Conference (ACSC), 27, 27-35. https://pdfs.semanticscholar.org/ff56/173b83c4b6d2b02687f82bd4da56337c97ec.pdf 
Houben, R., \& Snyers, A. (2018). Cryptocurrencies and blockchain: Legal context and implications for financial crime, money laundering and tax evasion. European Commission.

http://www.europarl.europa.eu/cmsdata/150761/TAX3\%20Study\%20on\%20cryptocur rencies\%20and\%20blockchain.pdf

Kaufmann, D., Kraay, A., \& Mastruzzi, M. (2011). The worldwide governance indicators: methodology and analytical issues. Hague Journal on the Rule of Law, 3(2), 220-246. doi.org/10.1017/S1876404511200046

Lansky, J. (2018). Possible state approaches to cryptocurrencies. Journal of Systems Integration, 9(1), 19-31. doi.org/10.20470/jsi.v9i1.33

Law Library of Congress (2018). Regulation of cryptocurrencies around the world. Available at: https://www.loc.gov/law/help/cryptocurrency/regulation-of-cryptocurrency.pdf

Levene, H. (1960). Robust tests for equality of variances. Standford University Press.

Marian, O. (2013). Are cryptocurrencies super tax havens. Michigan Law Review First Impressions, 112, 38. https://repository.law.umich.edu/mlr_fi/vol112/iss 1/2

Maupin, J. (2017). The G20 countries should engage with blockchain technologies to build an inclusive, transparent, and accountable digital economy for all. Economics Discussion Papers, 48. Kiel Institute for the World Economy. http://www.economicsejournal.org/economics/discussionpapers/2017-48

Nakamoto, S. (2008). Bitcoin: A peer-to-peer electronic cash system. https://bitcoin.org/bitcoin.pdf

Narayanan, A., Bonneau, J., Felten, E., Miller, A., \& Goldfeder, S. (2016). Bitcoin and cryptocurrency technologies: a comprehensive introduction. Princeton University Press.

New York State Department of Financial Services (2015). New York codes, rules and regulations, part 200, Virtual Currencies.

Nye, J. S. (1967). Corruption and political development: A cost-benefit analysis. American political science review, 61(2), 417-427. doi.org/10.2307/1953254

Omidi,M., Min, Q., \& Omidi, M. (2017). Combined effect on economic variables on fraud, a survey of developing countries. Economics and Sociology, 10(2), 267-278.

Pérez-Cárceles, M. C., \& Gómez-García, J. (2019). Goodness of governance effect on European banking efficiency. International Review of Economics \& Finance, 64, 29-40. doi.org/10.1016/j.iref.2019.05.016

Peters, G., Panayi, E., \& Chapelle, A. (2015). Trends in cryptocurrencies and blockchain technologies: a monetary theory and regulation perspective. Journal of Financial Perspectives, 3(3). papers.ssrn.com/sol3/papers.cfm?abstract_id $=3084011$

Picard, P. M., \& Pieretti, P. (2011). Bank secrecy, illicit money and offshore financial centers. Journal of public economics, 95(7-8), 942-955. https://econpapers.repec.org/article/eeepubeco/v_3a95_3ay_3a2011_3ai_3a78_3ap_3a942-955.htm

Rauchs, M., Blandin, A., Klein, K., Pieters, G. C., Recanatini, M., \& Zhang, B. Z. (2018). 2nd Global Cryptoasset Benchmarking Study. University of Cambridge. https://www.jbs.cam.ac.uk/fileadmin/user_upload/research/centres/alternativefinance/downloads/2019-06-ccaf-2nd-global-cryptoasset-benchmarking.pdf

Sandholtz, W., \& Koetzle, W. (2000). Accounting for corruption: Economic structure, democracy, and trade. International studies quarterly, 44(1), 31-50. https://www.jstor.org/stable/3013968?seq=1\#page_scan_tab_contents

Sockin, M., \& Xiong, W. (2020). A model of cryptocurrencies (No. w26816). National Bureau of Economic Research. 
Sovbetov, Y. (2018). Factors influencing cryptocurrency prices: Evidence from bitcoin, ethereum, dash, litcoin, and monero. Journal of Economics and Financial Analysis, 2(2), 1-27. https://papers.ssrn.com/sol3/papers.cfm?abstract_id=3125347

Swartz, N. D. (2014). Bursting the Bitcoin bubble: The case to regulate digital currency as a security or commodity. Tulane Journal of Technology and Intellectual Property, 17, 319. https://journals.tulane.edu/index.php/TIP/article/viewFile/2644/2466

Transparency International. (2019). Corruption Perceptions Index 2018. https://www.transparency.org/files/content/pages/CPI_2018_Executive_Summary_EN .pdf

Tobin, J. (1958). Estimation of Relationships for Limited Dependent Variables. Econometrica, 26(1), 24-36. $\quad$ https://www.jstor.org/stable/pdf/1907382.pdf ?seq=1\#page_scan_tab_contents

Velde, F. (2013). Bitcoin: A primer. https://econpapers.repec.org/article/fipfedhle/y_3a2013_3ai_3adec_3an_3a317.htm

Wolfson, S. N. (2015). Bitcoin: The early market. Journal of Business \& Economics Research (Online), 3(4), 201. https://clutejournals.com/index.php/ JBER/article/view/9452/0

World Bank. (2018). Cryptocurrencies and Blockchain. Europe and Central Asia Economic Update (May). World Bank. Washington, DC. http://documents.worldbank.org/curated/en/293821525702130886/pdf/Cryptocurrenci es-and-blockchain.pdf 


\section{Annexes}

Annex 1. Spearman's correlation matrix

\begin{tabular}{cccccccccccc}
\hline & $\mathrm{UC}$ & $\mathrm{GG}$ & $\mathrm{GG}_{1}$ & $\mathrm{VA}$ & $\mathrm{PS}$ & $\mathrm{GG}_{2}$ & $\mathrm{GE}$ & $\mathrm{RQ}$ & $\mathrm{GG}_{3}$ & $\mathrm{RL}$ & $\mathrm{CC}$ \\
\hline $\mathrm{UC}$ & 1.000 & $-0.652^{* *}$ & $-0.559^{* *}$ & $-0.601^{* *}$ & $-0.544^{* *}$ & $-0.644^{* *}$ & $-0.695^{* *}$ & $-0.606^{* *}$ & $-0.654^{* *}$ & $-0.658^{* * *}$ & $-0.636^{* *}$ \\
\hline $\mathrm{GG}$ & $-0.652^{* *}$ & 1.000 & $0.956^{* *}$ & $0.959^{* *}$ & $0.855^{* *}$ & $0.981^{* *}$ & $0.970^{* *}$ & $0.961^{* *}$ & $0.990^{* *}$ & $0.981^{* *}$ & $0.983^{* *}$ \\
\hline $\mathrm{GG}_{1}$ & $-0.559^{* *}$ & $0.956^{* *}$ & 1.000 & $0.928^{* *}$ & $0.943^{* *}$ & $0.916^{* *}$ & $0.911^{* *}$ & $0.893^{* *}$ & $0.932^{* *}$ & $0.920^{* *}$ & $0.936^{* *}$ \\
\hline $\mathrm{VA}$ & $-0.601^{* *}$ & $0.959^{* *}$ & $0.928^{* *}$ & 1.000 & $0.791^{* *}$ & $0.933^{* *}$ & $0.928^{* *}$ & $0.906^{* *}$ & $0.947^{* *}$ & $0.940^{* *}$ & $0.950^{* *}$ \\
\hline $\mathrm{PS}$ & $-0.544^{* *}$ & $0.855^{* *}$ & $0.943^{* *}$ & $0.791^{* *}$ & 1.000 & $0.822^{* *}$ & $0.825^{* *}$ & $0.796^{* *}$ & $0.822^{* *}$ & $0.808^{* *}$ & $0.825^{* *}$ \\
\hline $\mathrm{GG}_{2}$ & $-0.644^{* *}$ & $0.981^{* *}$ & $0.916^{* *}$ & $0.933^{* *}$ & $0.822^{* *}$ & 1.000 & $0.974^{* *}$ & $0.980^{* *}$ & $0.973^{* *}$ & $0.964^{* *}$ & $0.962^{* *}$ \\
\hline $\mathrm{GE}$ & $-0.695^{* *}$ & $0.970^{* *}$ & $0.911^{* *}$ & $0.928^{* *}$ & $0.825^{* *}$ & $0.974^{* *}$ & 1.000 & $0.927^{* *}$ & $0.973^{* *}$ & $0.973^{* *}$ & $0.955^{* *}$ \\
\hline $\mathrm{RQ}$ & $-0.606^{* *}$ & $0.961^{* *}$ & $0.893^{* *}$ & $0.906^{* *}$ & $0.796^{* *}$ & $0.980^{* *}$ & $0.927^{* *}$ & 1.000 & $.953^{* *}$ & $0.933^{* *}$ & $0.946^{* *}$ \\
\hline $\mathrm{GG}$ & $-0.654^{* *}$ & $0.990^{* *}$ & $0.932^{* *}$ & $0.947^{* *}$ & $0.822^{* *}$ & $0.973^{* *}$ & $0.973^{* *}$ & $0.953^{* *}$ & 1.000 & $0.987^{* *}$ & $0.991^{* *}$ \\
\hline $\mathrm{RL}$ & $-0.658^{* *}$ & $0.981^{* *}$ & $0.920^{* *}$ & $0.940^{* * *}$ & $0.808^{* *}$ & $0.964^{* *}$ & $0.973^{* *}$ & $0.933^{* *}$ & $0.987^{* *}$ & 1.000 & $0.969^{* *}$ \\
\hline $\mathrm{CC}$ & $-0.636^{* *}$ & $0.983^{* *}$ & $0.936^{* *}$ & $0.950^{* *}$ & $0.825^{* *}$ & $0.962^{* *}$ & $0.955^{* *}$ & $0.946^{* *}$ & $0.991^{* *}$ & $0.969^{* *}$ & 1.000 \\
\hline & & & & & & & & & & &
\end{tabular}

Annex 2. Pearson's correlation matrix

\begin{tabular}{|c|c|c|c|c|c|c|c|c|c|c|c|}
\hline & $\mathrm{UC}$ & GG & $\overline{\mathrm{GG}_{1}}$ & VA & PS & $\mathrm{GG}_{2}$ & GE & RQ & $\mathrm{GG}_{3}$ & $\mathrm{RL}$ & $\mathrm{CC}$ \\
\hline $\mathrm{UC}$ & 1 & $-0.703^{* *}$ & $-0.682^{* *}$ & $-0.620^{* *}$ & $-0.693^{* *}$ & $-0.693^{* *}$ & $-0.727^{* *}$ & $-0.643^{* *}$ & $-0.685^{* *}$ & $-0.700^{\text {** }}$ & $-0.660^{\text {** }}$ \\
\hline GG & $-0.703^{* * *}$ & 1 & $0.952^{* * *}$ & $0.932^{* * *}$ & $0.909^{* * *}$ & $0.987^{* * *}$ & $0.978^{* * *}$ & $0.972^{* *}$ & $0.988^{* * *}$ & $0.987^{* * *}$ & $0.973^{* *}$ \\
\hline $\mathrm{GG}_{1}$ & $-0.682^{* *}$ & $0.952^{* *}$ & 1 & $0.961^{* *}$ & $0.971^{* *}$ & $0.904^{* *}$ & $0.891^{* *}$ & $0.894^{* *}$ & $0.899^{* *}$ & $0.910^{* *}$ & $0.876^{* *}$ \\
\hline VA & $-0.620^{\text {** }}$ & $0.932^{* *}$ & $0.961^{* *}$ & 1 & $0.867^{* *}$ & $0.882^{* *}$ & $0.863^{* *}$ & $0.878^{* * *}$ & $0.897^{* *}$ & $0.902^{* * *}$ & $0.879^{* * *}$ \\
\hline PS & $-0.693^{\text {** }}$ & $0.909^{* * *}$ & $0.971^{* *}$ & $0.867^{* * *}$ & 1 & $0.866^{* * *}$ & $0.858^{* * *}$ & $0.851^{* *}$ & $0.845^{* * *}$ & $0.859^{* * *}$ & $0.820^{* * *}$ \\
\hline $\mathrm{GG}_{2}$ & $-0.693^{* *}$ & $0.987^{* *}$ & $0.904^{* *}$ & $0.882^{* *}$ & $0.866^{* *}$ & 1 & $0.987^{* *}$ & $0.988^{* *}$ & $0.982^{* *}$ & $0.982^{* *}$ & $0.967^{* *}$ \\
\hline GE & $-0.727^{* *}$ & $0.978^{* *}$ & $0.891^{* * *}$ & $0.863^{* * *}$ & $0.858^{* * *}$ & $0.987^{* * *}$ & 1 & $0.950^{* * *}$ & $0.979^{* *}$ & $0.982^{* *}$ & $0.962^{* *}$ \\
\hline RQ & $-0.643^{* *}$ & $0.972^{* *}$ & $0.894^{* *}$ & $0.878^{* *}$ & $0.851^{* *}$ & $0.988^{* * *}$ & $0.950^{* *}$ & 1 & $0.961^{* *}$ & $0.958^{* *}$ & $0.948^{* *}$ \\
\hline $\mathrm{GG}_{3}$ & $-0.685^{\text {** }}$ & $0.988^{* * *}$ & $0.899^{* * *}$ & $0.897^{* *}$ & $0.845^{* *}$ & $0.982^{* *}$ & $0.979^{* *}$ & $0.961^{* *}$ & 1 & $0.991^{* * *}$ & $0.993^{* *}$ \\
\hline RL & $-0.700^{* * *}$ & $0.987^{* *}$ & $0.910^{* *}$ & $0.902^{* *}$ & $0.859^{* *}$ & $0.982^{* *}$ & $0.982^{* *}$ & $0.958^{* *}$ & $0.991^{* *}$ & 1 & $0.967^{* *}$ \\
\hline $\mathrm{CC}$ & $-0.660^{* *}$ & $0.973^{* *}$ & $0.876^{* *}$ & $0.879^{* *}$ & $0.820^{* *}$ & $0.967^{* *}$ & $0.962^{* *}$ & $0.948^{* *}$ & $0.993^{* *}$ & $0.967^{* *}$ & 1 \\
\hline
\end{tabular}

Annex 3. Test for equal means

\begin{tabular}{|c|c|c|c|c|c|}
\hline \multirow[b]{2}{*}{ Variable } & \multirow[b]{2}{*}{$\begin{array}{l}\text { Levene's test } \\
\text { (F-statistic) }\end{array}$} & \multicolumn{4}{|c|}{ t-test for equal means } \\
\hline & & $\begin{array}{l}\text { t-statistic } \\
\text { (d.f.) }\end{array}$ & Mean difference & $\begin{array}{c}\text { Lower } \\
\text { Conf. int. (95\%) }\end{array}$ & $\begin{array}{c}\text { Upper } \\
\text { Conf. int. }(95 \%)\end{array}$ \\
\hline GG & $16.486 * * *$ & $\begin{array}{c}-3.795^{* * *} \\
(24.645)\end{array}$ & -5.035 & -7.769 & -2.301 \\
\hline $\mathrm{GG}_{1}$ & $14.529 * * *$ & $\begin{array}{c}-3.209 * * * \\
(21.441) \\
\end{array}$ & -1.329 & -2.189 & -0.469 \\
\hline VA & $9.213 * * *$ & $\begin{array}{c}-3.230 * * * \\
(20.942) \\
\end{array}$ & -0.640 & -1.053 & -0.228 \\
\hline PS & $11.576^{* * *}$ & $\begin{array}{c}-2.927 * * * \\
(23.552)\end{array}$ & -0.689 & $-1,175$ & $-0,203$ \\
\hline $\mathrm{GG}_{2}$ & $13.731 * * *$ & $\begin{array}{c}-3.941 * * * \\
(25.844)\end{array}$ & -1.635 & -2.487 & -0.782 \\
\hline GE & $9.347 * * *$ & $\begin{array}{c}-3.798 * * * \\
(27.129)\end{array}$ & -0.789 & -1.215 & -0.363 \\
\hline RQ & $12.808 * * *$ & $\begin{array}{c}-3.936^{* * * *} \\
(24.835)\end{array}$ & -0.846 & -1.289 & -0.403 \\
\hline $\mathrm{GG}_{3}$ & $8.594 * * *$ & $\begin{array}{c}-3.824 * * * \\
(26.918)\end{array}$ & -2.071 & -3.182 & -0.959 \\
\hline RL & $15.904 * * *$ & $\begin{array}{c}-3.743 * * * \\
(25.297) \\
\end{array}$ & -0.965 & -1.497 & -0.434 \\
\hline $\mathrm{CC}$ & $3.592 * *$ & $\begin{array}{c}-3.808 * * * \\
(28.578)\end{array}$ & -1.105 & -1.699 & -0.511 \\
\hline
\end{tabular}

***: $0.01 ; * *: 0.05$

Source: own calculation 